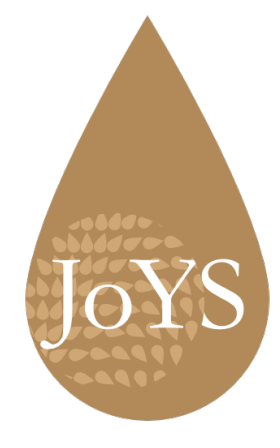

\title{
EDITORIAL: INAUGURATING JOYS
}

Dear Readers,

Welcome to the Journal of Yoga Studies, or JoYS, its auspicious acronym.

This Journal has been a long time coming. I remember discussing such a possibility with colleagues and publishing houses around the year 2000. Disheartened by the commercially exploitative stance of many publishers, however, we did not go ahead at that time. But now that the open access world of publishing has flourished we feel ready to do so. Even though, having just closely followed both the conceptual and the technical processes involved in accompanying two articles all the way from the mind of their authors to fully finished, publishable products, I have a bit more sympathy for the publishing houses. I still think that there has been (and that there still is) too much commercial exploitation of academics' work in the context of academic publishing, but I also realise much more poignantly that bringing to fruition a high quality, aesthetically pleasing product does require substantial amounts of time, financial investment, administrative work and painstaking attention.

I truly hope that JoYS' readers will be able to both enjoy and benefit from our efforts, especially at a time when 'yoga' has become so popular that all manner of texts are written about it, electronically or otherwise. Contrary to this trend, we are keen to prioritise quality rather than quantity, research-based accuracy and deliberation rather than superficial or partial views. We aim to present only carefully selected, peerreviewed, well-presented open access articles from all areas of the Humanities and the 


\section{JOURNAL OF \\ YOGA STUDIES}

2018 • Volume 1

Social Sciences: trustworthy contributions which can help generate understanding and informed, open-minded reflection and discussion. To this effect, we plan to publish both stand alone research articles (such as the first two published), and what we call "Article Sets": sequentially published, in-depth, theoretically and critically oriented texts in which foundational yoga-related themes are discussed by top area specialists. And of course we will publish book reviews (with thanks to Matylda Ciołkosz for agreeing to be our Book Reviews Editor). In due course we will be evaluating the possibility of offering JoYS also in print format, but in any case from the launch onward all contributions will be available to readers for download as printable pdfs. No article processing fees will be charged for publication, and authors will retain full copyright of their work.

With regard to the first series of Article Sets we are hoping to start by tackling a subject which is currently much debated in the world of academic yoga research: that of the "authorship of the Yogasūtra". Far from being 'only' philologically and historically intriguing, such a topic brings up many deeper issues relating to underlying academic presuppositions, methodological choices, ideological positionings and scholarly thought genealogies. I am sure many, like me, are looking forward to hearing more about this.

As for book reviews, we thought that, in the case of especially important contributions to our field, we may apply a "Special Focus": a formula that would mean simultaneously publishing reviews of a title by three different reviewers, thus providing a rich, layered, multi-faceted analysis of the work in question. As yet, however, this is still only a tentative idea. For a start, it may not be so easy to draft in three different specialist reviewers at the same time!

Another wish we have is to attempt to bridge some of the many geographicoconceptual gaps that divide the academic world. One such, and a very relevant one for us, would definitely be the 'major' East-West one (with apologies for using such an old fashioned and much criticised dichotomy). Very possibly some Article Set contributions will provide us with food for thought in this context. Otherwise, something perhaps more manageable will be to attempt, at least occasionally, to bridge divides that are closer to home: Europe East and West, or Anglo-Germanic versus Latin languages scholarship. This is why, given the right conditions, we may publish translations or articles in languages other than English. Such exercises could be enriching in more ways than one, but also challenging on both conceptual and technical implementation levels. 


\section{JOURNAL OF \\ YOGA STUDIES}

2018 • Volume 1

In keeping with our international, cross-boundary outlook, several launch events and presentations have been organised around the world to mark the launch of our Journal. At the time of writing, a short introductory presentation by JoYS' first published authors Philip Deslippe and Seth Powell has already taken place on 28th February 2018 at Loyola Marymount University in Los Angeles, courtesy of Prof. Christopher Chapple. We expect JoYS to also be presented, courtesy of Prof. James Mallinson, in the context of the 8th May 2018 opening of SOAS' new Centre of Yoga Studies. As for Asia, two launch events will be taking place at Kyoto University (on 8th May 2018, courtesy of Prof. Somdev Vasudeva), and at Studio Abhyas in Delhi (on 10th May 2018, courtesy of Navtej Singh Johar). Our own Jason Birch will be giving lectures at these two events, on Yogis on their Heads: The History of Headstand in the Early Modern Period in Kyoto, and on A History of Pre-Modern Āsana in Delhi. We are grateful to all these institutions for their sympathy and participation.

It is also fitting to gratefully acknowledge here the financial support that the AMRAY (Association Monégasque pour la Recherche Académique sur le Yoga) has generously offered to support JoYS' creation and ongoing work. This means that we will be able to remunerate some core editorial work - though probably nowhere near as much as would be deserved. The peer-reviewed, journal-related aspects of academics' work, while playing a key role in terms of quality control, article content enhancement and dissemination of new research, usually go as unrewarded and as unacknowledged as most homemakers' toil. So it is particularly satisfying to be able to go slightly against the flow here, and offer some financial compensation for the important work carried out. We are keeping an eye on the accounts and, depending on how things go, we may also be able to offer small compensations to our article and book reviewers. This too would be a welcome departure from current practice. Perhaps others will follow our lead.

On a personal note, I would like to thank my four JoYS co-founders for accepting to participate in, and for motivating me, to undertake this adventure. It is a real privilege to have them as collaborators, and their multiple and diverse abilities do not cease to amaze me, while I also find their unique and personal manifestations of intelligence, resourcefulness and sense of humour both instructive and entertaining.

Last but definitely not least, all of JoYS' founding members would like to gratefully acknowledge the encouragement and support provided from the very start by our esteemed Advisory and Editorial Boards, by our Academic Partners, as well as the yetto-come contributions of any non-board academics that may act as reviewers in future. 
Without your collaboration, trust and confidence (and in some cases friendship) JoYS' work would not make sense, and the Journal could not survive.

May our work and all authors' contributions benefit the academic community and beyond!

Elizabeth De Michelis on behalf of all JoYs founding members:

Jason Birch

Matthew Clark

Jacqueline Hargreaves

Suzanne Newcombe 